\title{
Governance Challenges in the Mediterranean
}

\author{
Harry Coccossis, University of Thessaly, Greece
}

\begin{abstract}
The Mediterranean benefits from a long tradition in environmental cooperation under the Barcelona Convention and its operational mechanism The Mediterranean Action Plan of UNEP. Such cooperation focused at an early stage on the protection of the marine and coastal environment with a major emphasis on regulation through the Convention and its seven Protocols. In this context ICZM has acquired a special attention through a recent innovative Protocol. However, the environmental policy agenda has been broadened and moved higher up the governance levels giving priority for example to global issues such as climate change and to supra-national (i.e. EU) or international level commitments (i.e. the Kyoto protocol). In addition sustainable development perspectives have brought environmental integration issues in sectoral/development policies. As a consequence national, regional and local authorities are faced with an increasingly complex structure of policies, programmes, activities, initiatives and stakeholders (World Bank, GEF, UfM, etc.). Governance improvement has been central to these concerns in the Mediterranean particularly in terms of key themes of interest: pollution, biodiversity and coastal zone management
\end{abstract}

